\title{
NEW LOCI IN THE SEX CHROMOSOME OF THE FOWL*
}

F. B. HUTT

Department of Poultry Husbandry, New York State College of Agriculture, Cornell University, Ithaca, New York

Received I2.i.6o

\section{INTRODUCTION}

THE first tentative map for the fowl's sex chromosome showed the approximate locations of seven genes (Hutt, I936). In a pictorial map published I3 years later (Hutt, I949) only one gene could be added (Munro's sex-linked dilution), but even for that the exact locus was uncertain, as it still is. However, the studies of Punnett (I940) permitted some helpful revision, particularly in locating the gene Id. Moreover, by 1949 three additional sex-linked mutations were known--naked, albinism and dwarf-but their positions in the chromosomes were not.

From tests for linkage carried out during the past 22 years, together with the contributions of Mueller (I952) and Cole (I958), it is now possible to add five new loci to the map of the sex chromosome, and to extend it considerably beyond its earlier limits.

\section{THE MUTATIONS INVOLVED}

The mutants here considered have all been described in some detail earlier, hence only brief notes about them should be necessary in this report. The dominant genes $B, S$ and $K$, which cause barring, silver and slow feathering, respectively, are old friends familiar to all fowl geneticists, and were already spotted in earlier maps. The others, all of which are recessive, are as follows :-

Albinism, al (Mueller and Hutt, I94I). This is an imperfect albinism. Chicks have bright pink eyes when hatched, but in adults the iris is blue-grey, and barred birds show faint ghost-barring in the plumage. In the eye, melanin is restricted to the pigment layer of the retina and the retinal portions of the ciliary body and iris. Vision and viability are apparently normal.

Dwarf, dw (Hutt, I949, I959). This gene reduces the size of adult females by about $3^{\circ}$ per cent. and that of homozygous males by about 43 per cent., but chicks that become dwarfs are of normal size at hatching. Their viability and reproduction are normal except that dwarf hens lay somewhat fewer and smaller eggs than their normal sisters.

Paroxysm, $p x$ (Cole, I958). At various times after Io days of age,

* Number 28 in the author's series entitled "Genetics of the Fowl". 
females carrying $p x$ will react to sudden disturbance by throwing the head over the back, becoming rigid and beating the wings violently. Such a paroxysm lasts ro to i 5 seconds, after which the chick relaxes. None survive more than a few weeks.

Naked, $n$ (Hutt and Sturkie, I938). Affected females are bare at hatching, or show a little down, but are usually all bare by four weeks of age when the down has been lost. Some adults are bare, others almost normal except for missing or defective remiges. Homozygous males are affected less than the hemizygous females. About half the naked chicks die during the last two or three days of incubation, and others after hatching, so that without extra care only slightly more than 25 per cent. of the zygotes are raised to maturity.

Shaker, sh (Scott et al., I950). Affected birds show at two to five weeks of age very rapid quivering of the head and neck. Incoordination of movements becomes progressively worse and by I 4 weeks most shakers cannot stand. Only a few survive to sexual maturity. Purkinje cells of the cerebellum are absent or degenerated.

\section{PROCEDURES}

Apart from the usual handicap that crossing-over between sex-linked genes can be measured only in gametes of the homogametic sex, linkage studies with these five genes are complicated by the facts that three of them are lethal $(p x, n$ and $s h)$, one delayed in expression $(d w)$, and two ( $a l$ and $n$ ) prevent the manifestation of some other sex-linked genes. As doubly recessive females in some combinations could not be raised to breeding age, and in others were difficult to maintain, the general practice was to test dihybrid or trihybrid males, which were mated to normal females, usually White Leghorns or New Hampshires. From such matings only the female progeny could be used to measure crossingover in the gametes of their sires.

Because of all these limitations, most tests were repeated several times and with different males, not only to increase the numbers of gametes tested, but also to determine whether or not consistent results could be obtained.

\section{LINKAGE OF AL}

(i) With $K$. The $\kappa-k$ alleles causing slow feathering and rapid feathering, respectively, are evident in most chicks at hatching, but are perhaps more accurately distinguished at io days of age. Even then, there are usually a few that are difficult to classify. In all linkage studies involving these genes, descriptions were recorded both at hatching and Io days later. Since in most tests the chance of being a cross-over ranged only from 2 to 18 per cent., no chick was considered as such unless its description at Io days agreed with that at hatching.

In tests not complicated by other genes, al showed only $\mathrm{r} \cdot 8$ per cent. crossing-over with $K$ in 274 gametes from 3 males (table r).

This same relationship was also measured in gametes from 5 males 
of the genotype $A l k n / a l K \mathcal{N}$. These males are indicated in table $\mathrm{r}$ by asterisks $(*)$ with one parental class. As $K$ and $k$ cannot be classified in naked chicks, only about half the female progeny (those carrying $\mathcal{N}$ and alive at ro days) could be used for this test. It will be noted that, among these, one parental class, al $K \mathcal{N}$, is over four times as frequent as the other. This disparity results from the fact that the parental class $A l k n$, being naked, would be completely unidentifiable (as $K$ or $k$ ) if linkage of these 3 genes were complete. Gametes carrying the parental combination $A l k$ can be identified only as a result of crossingover between $k$ and $n$, which yielded 53 chicks of the recognisable genotype $A l k \mathcal{N}$. Cross-overs in 288 gametes from these 5 males numbered only 4 , or I 4 per cent.

Considering all 8 matings together, crossing-over between $a l$ and $K$ in 562 gametes was $\mathrm{I} \cdot 6$ per cent.

(ii) With $n$. Regardless of its shortcomings for tests of linkage with other genes, $n$ is very satisfactory for tests with al. Lethal action of $n$ on developing embryos is not exerted until the last 3 days of incubation, and mostly in the last two. There is usually a shortage of naked chicks among those hatched, but, on examination of the dead-in-shell, it is easy to identify naked, albinotic and normal chicks that have died late in incubation. The first two of these classes must be females, if from normal mothers, as were all those considered in table r. By dissection of the normal chicks, any $A l \mathcal{N}$ females among the dead-in-shell are identified. When sexes of the normal chicks that hatched are determined, one has thus a complete record for all females that were alive at i 8 days of incubation.

To save space, records are not given separately here for the deadin-shell and hatched chicks. As the data show (table I), the observed ratios of $A l: a l(376: 372)$ and $\mathcal{N}: n(373: 375)$ are so close to the expected I : I that they might well be viewed with suspicion.

Crossing-over between al and $n$ in 748 gametes from 6 males was I 7.6 per cent., and the separate determinations for each male were reasonably consistent.

(iii) With dw. As dwarfs cannot all be accurately classified until four or five months of age, there is always the difficulty that mortality before that age reduces numbers somewhat, and the risk that some other mutation, when combined with dwarfism, might cause disproportionate reduction of the double recessive class. Fortunately that did not happen in these tests, and there was even an excess of albinotic dwarfs above the number for the other cross-over class (table I). Crossing-over in 270 gametes from the two males tested was 7 per cent.

(iv) Order of the genes al, $K$ and $n$. It was evident that $n$ is more remote from al than $K$ is, but the question whether or not the latter gene lies between the other two had to be answered. The 5 triply heterozygous males starred in table I were useful for that purpose.

If their three linked genes were arranged $k_{\text {I }} \cdot 6 \mathrm{Al}$ I $7 \cdot 6 \mathrm{n} / \mathrm{K}_{\mathrm{I}} \cdot 6 \mathrm{al}$ G 2 
I $7.6 \mathcal{N}$, then recognisable $(\mathcal{N})$ single cross-overs between $K$ and al would be $k$ al $\mathcal{N}$ and the number expected in 288 gametes would be $4 \cdot 6$. Double cross-overs, $K A l \mathcal{N}$, should number theoretically only $0 \cdot 8$.

TABLE I

Tests for linkage of al

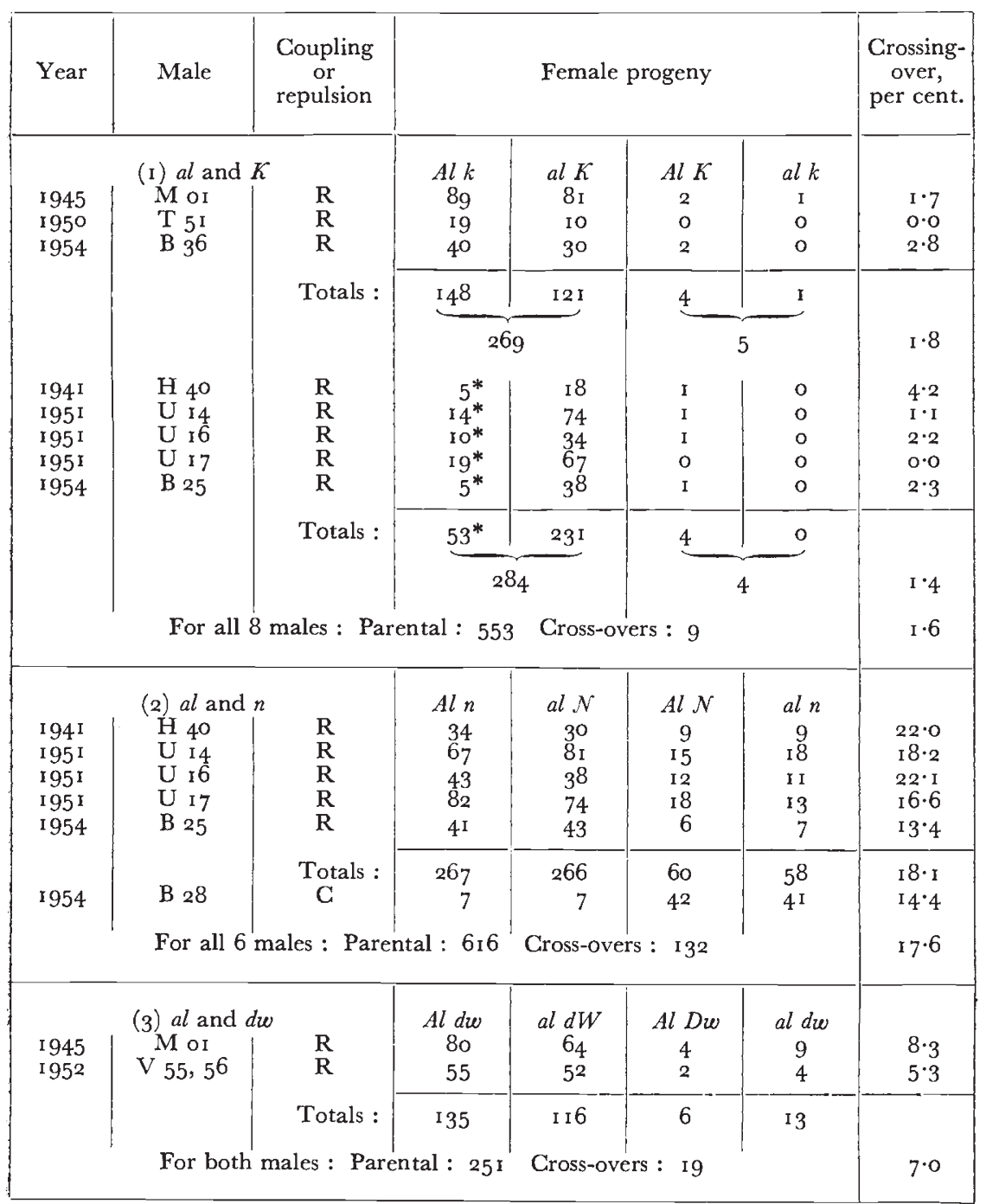

* For explanation of apparent deficiency of this parental class, see context.

With the alternative order, $A l-k-n / a l-K-\mathcal{N}$, these classes are reversed, and single cross-overs between $a l$ and $K$ should yield 4 or $5 A l K \mathcal{N}$ chicks but hardly any of the al $k \mathcal{N}$ double cross-overs. The observed numbers in these two classes, 4 and o, make the second arrangement the more likely one. 


\section{LINKAGE OF DW}

In addition to the tests of dw with al considered in the previous section, the former gene was also tested with $B$ (barring), $S$ (silver) and $\kappa$ (table 2).

TABLE 2

Tests for linkage of $\mathrm{dw}$

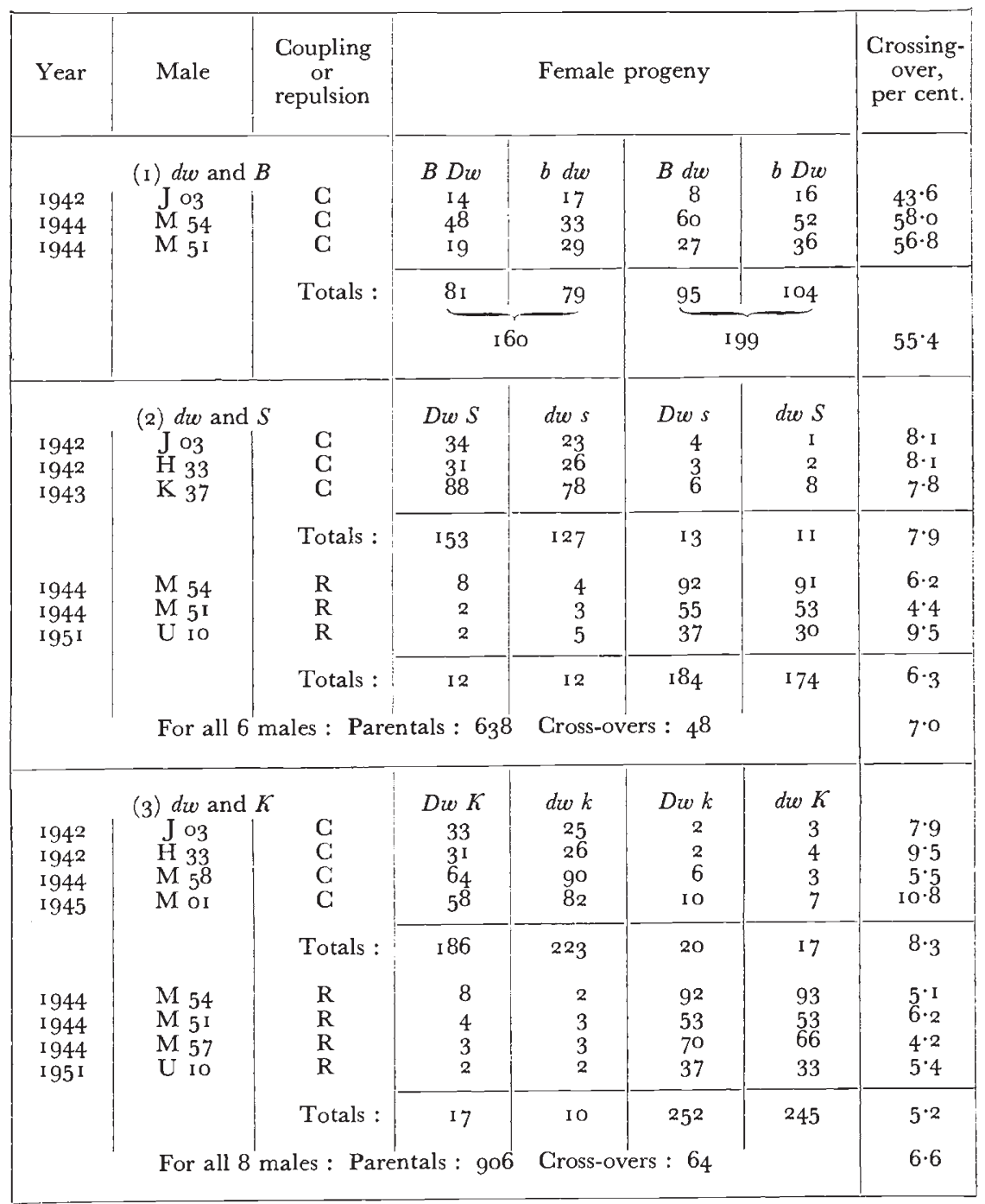

(i) With $B$. In 359 gametes from 3 males, cross-overs between $B$ and $d w$ numbered 55.4 per cent. As the ratios of $176 B: 183 b$ and I $85 D w:$ I $74 d w$ are close to those of I : I expected, it seems probable that the slight excess of cross-overs above the theoretical maximum of $5^{0}$ per cent. cannot be attributed to differential viability of any one class, or to errors of classification, but only to chance. These tests 
showed that $d w$ is not only remote from $B$, but also more likely to be beyond $K$ than between $B$ and $K$, and this arrangement was later verified.

(ii) With $S$. Among 686 females classified in these tests, cross-overs between $S$ and $d w$ numbered only 48 , or $7 \cdot 0$ per cent., and separate determinations for the 6 males were reasonably consistent. The ratio of $350 S: 336 s$ fits expectation well. There are usually a few birds difficult to classify as silver or gold, but the ratios recorded in the crossover classes indicate that any error from that source must have been insignificant.

(iii) With $K$. This relationship was measured in 970 gametes. Determinations for the 8 different males ranged from $4 \cdot 2$ to 10.8 per cent., the overall figure being $6 \cdot 6$ per cent.

\section{LINKAGE OF $N$}

(i) With $B$. As barring can be recognised at hatching (in chicks with extended black) by the white head spot, it was easy to get adequate numbers to test possible linkage of $B$ with $n$. It is usually possible to classify coloured, naked chicks as barred or non-barred because the head spot shows as a cluster of unpigmented feather follicles. The other follicles, even without down, do show pigment. However, it was shown by early tests, and confirmed in later ones, that these genes are too far apart to show even a loose linkage. There is little point in giving separate determinations for each of the 6 males used in these tests and, accordingly, the data for all six have been combined (table 3 ).

They show $5 \mathrm{I} \cdot 8$ per cent. crossing-over in $35 \mathrm{I}$ gametes. The deficiency of naked chicks $(202 \mathcal{N}:$ I $49 n)$ resulted in part from greater mortality in that class late in incubation, but also from the fact that $B$ and $b$ could sometimes not be recognised until the chicks had grown more feathers than they had at hatching. By that time their numbers were reduced. This does not affect the validity of the test for linkage because any reduction should affect equally one parental class and one cross-over class. Separate determinations for the normal chicks only and for naked chicks only are $5^{\mathrm{I}} \cdot 9$ and $5 \mathrm{I} \cdot 7$ per cent.

(ii) With $S$. This test was more difficult because the silver and gold alleles were seldom distinguishable at hatching in the naked chicks. Many of them died before acquiring enough feathers to show silver or gold, and, even with some comparatively well-feathered ones, classification was difficult. The more accurate measure of crossing-over between $S$ and $n$ is therefore obtained by considering only the parental and cross-over classes containing chicks not naked.

In I92 of these from 6 males (table 3 ) cross-overs numbered 4I, or 2 I 4 per cent. Among the 62 naked chicks, $25 \cdot 8$ per cent. were classified as cross-overs.

(iii) With $K$. It was impossible to distinguish in naked chicks between those carrying $K$ and their sisters with rapid feathering, hence crossing-over could be measured only in the females with 
normal plumage. Only a quarter of the gametes from each sire could thus be utilised, but over the years it was possible to get records for 748 classifiable gametes from 16 different males. Among these $17 \cdot 6$ per cent. were classified as cross-overs (table 3 ).

Four of these males used in I $94^{\circ}$ which had comparatively small

TABLE 3

Tests for linkage of $\mathrm{n}$

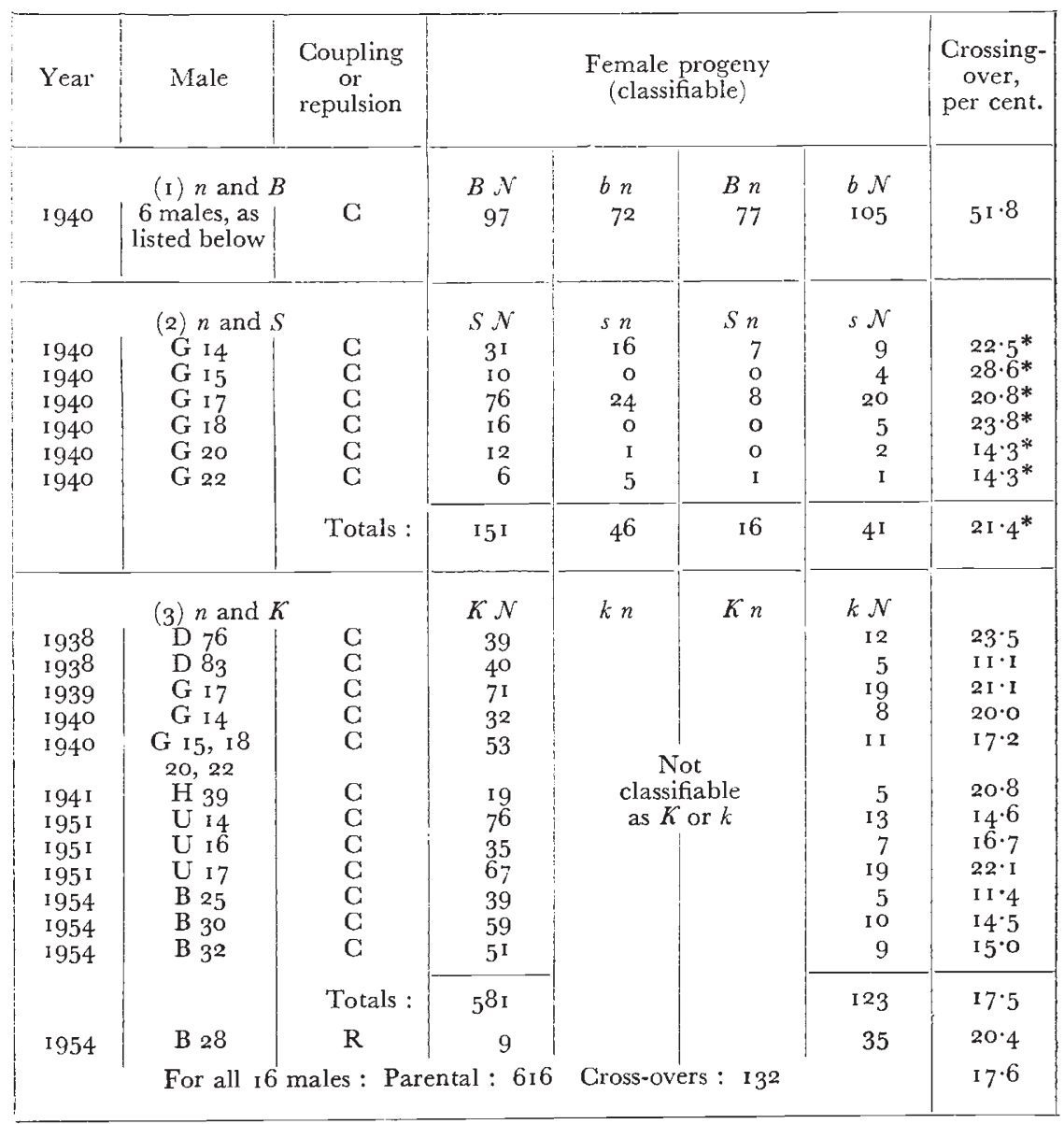

* In gametes carrying $\mathcal{N}$.

families have been grouped together in the table. Among the other I 2 males, recorded cross-overs varied from II $\cdot \mathrm{I}_{\mathrm{I}}$ to 23.5 . While much of this variation is attributable to chance in comparatively small numbers, and some, perhaps, to actual differences among sires in rate of crossing-over, it must be recognised that some of it may have resulted from faulty classification. There are usually a few chicks that are difficult (for this author) to classify as $K$ or $k$. On the other hand, as the $17 \cdot 6$ per cent. figure for the $\kappa-n$ relationship is identical with that 
for $a l$ and $n$, and $K$ and $a l$ are separated only by $\mathrm{I} \cdot 6$ cross-over units, these three determinations are in close agreement, and, as will be shown later, must indicate fairly accurately the loci for $a l, K$ and $n$.

\section{LINKAGE OF SH}

By kindness of Dr. C. D. Mueller, then at Kansas State College, we received in $195^{2}$ six males so bred that for each the chance of being heterozygous for the gene sh was better than 50 per cent. Two of

TABLE 4

Tests for linkage of $\mathrm{sh}$

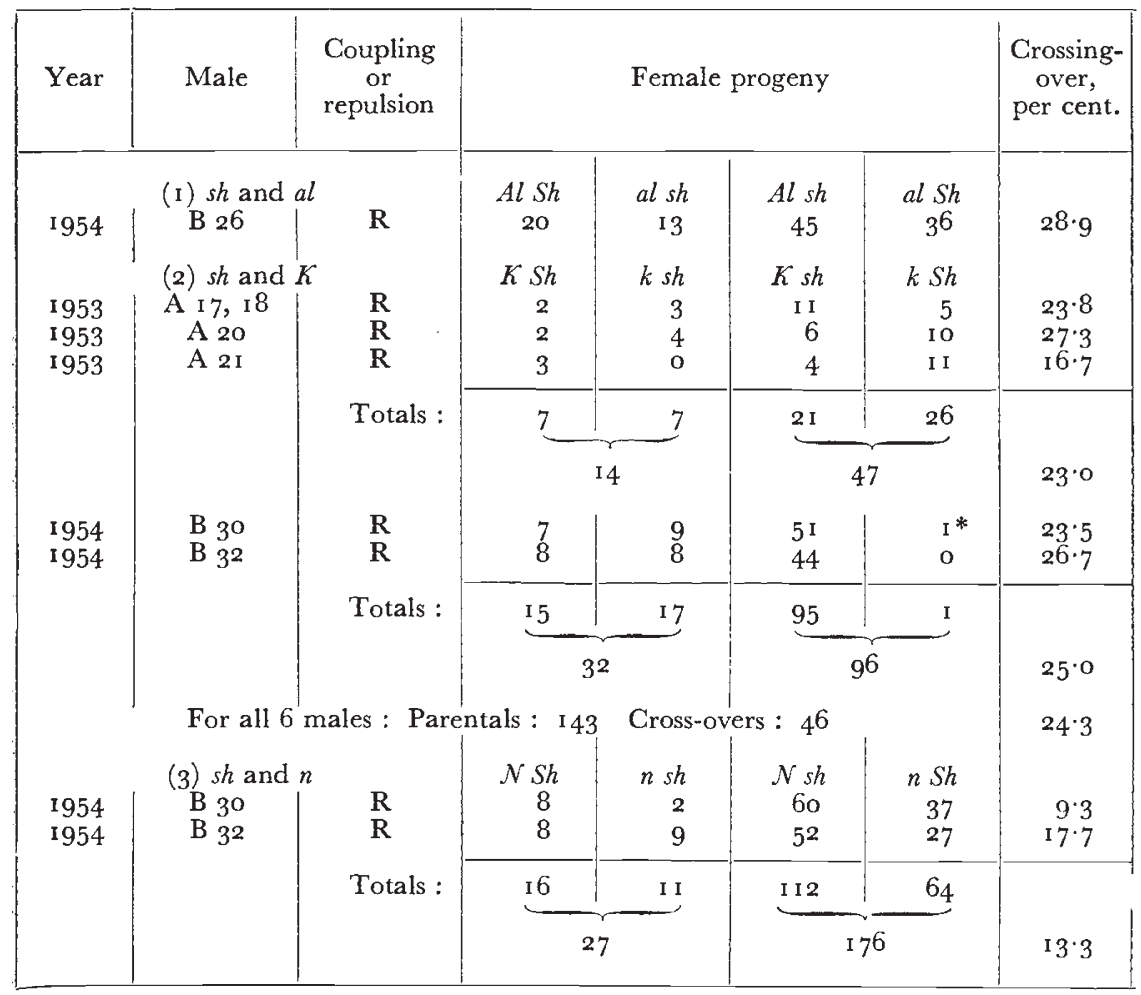

* For explanation of this chick, see context.

these were mated in 1953 with albinos, and four were tested (by artificial insemination) with naked females. Four of the six proved to be $K s h / k S h$, and these provided that year some evidence on distance between those two loci. Among their sons, further testing revealed one that carried sh and $a l$, and two carrying $s h$ and $n$. These three were then used in I954 to provide data on the linkage relations of $s h$ with al, $K$ and $n$ (table 4 ). As before, crossing-over could be measured only in their daughters.

(i) With al. In I I 4 gametes from the one male tested, cross-overs numbered 33 , or 28.9 per cent. There was a slight deficiency of 
albinos, particularly in the double-recessive (cross-over) class, but not more than could have occurred by chance.

(ii) With $K$. The four males found in 1953 to carry sh also proved to be heterozygous for $K$ and $k$. As these matings were made on only a limited scale, comparatively few female offspring were available, but among $6 \mathrm{I}$ of these there were 23 per cent. cross-overs. These matings were uncomplicated by the presence of other sex-linked genes.

The two males used in I 954 were of the genotype $K \mathcal{N} s h / k n S h$, and. they produced daughters as follows :-

\begin{tabular}{|c|c|}
\hline$\kappa \mathcal{N} s h$ & Parental \\
\hline$k \mathcal{N} s h$ & Cross-over, $k-n$ \\
\hline$\kappa \mathcal{N} S h$ & Cross-over, $\mathcal{N}$-sh \\
\hline$k \mathcal{N} S h$ & Double cross-over \\
\hline $\begin{array}{l}k n S h \\
K n S h\end{array}$ & $\left.\begin{array}{l}\text { Parental } \\
\text { Cross-over, } k-n\end{array}\right\}$ \\
\hline $\begin{array}{l}k n s h \\
K n s h\end{array}$ & $\begin{array}{l}\text { Cross-over, } n \text {-sh } \\
\text { Double cross-over }\end{array}$ \\
\hline
\end{tabular}

Separate data for each male are given in table 4. The number of $\mathcal{N}$ offspring given there is one less than that for the same matings in table 3 because one chick died before an age at which it could show the shaker mutation. Considering only the first 4 classes listed above (since $K$ and $k$ cannot be distinguished in the naked chicks of the other four groups), and counting the lone double cross-over between $K$ and $s h$ as a parental gamete with respect to those two genes, cross-overs between $\mathrm{K}$ and $s h$ numbered 32 in I 28 gametes, or $25^{\circ} \mathrm{o}$ per cent.

This figure agrees well with that of $26 \cdot 4$ per cent. determined by Mueller (r952), who measured crossing-over between $K$ and $s h$ in 87 gametes.

(iii) With $n$. Lethal action of $n$, either late in incubation, or after hatching and before an age at which sh could be manifested, considerably reduced the numbers of naked chicks from these matings, as the ratio of I $28 \mathcal{N}: 75 n$ shows. There is no indication, however, that the naked shakers were more adversely affected than those not naked. Accordingly, assuming that, apart from chance fluctuation in comparatively small numbers, the parental and cross-over classes carrying. $n$ were reduced in equal proportions, all four classes can be utilised to measure crossing-over. On this basis there were I3.3 per cent. crossovers in 203 gametes. Separate determinations for $\mathcal{N}$ and $n$ chicks only yielded I $2 \cdot 5$ and I $_{4} \cdot 6$, respectively.

(iv) Double cross-overs. Only one among the $128 \mathcal{N}$ chicks listed above was classified as $k \mathcal{N} S h$, i.e. the result of double crossing-over between $K$ and $s h$. With distances $K$ i $7.6 n$ i $3.3 s h$ the expected number of such chicks (without any interference) was three. 


\section{LINKAGE OF $K$ AND $S$}

Before proceeding to construction of a map for the sex chromosome, some reconsideration is necessary of the linkage relations of $K$ with other genes. The earlier results of several workers, when added to his own, led Punnett (I940) to place $K$ remote from $B$, below $S$, and showing about 15 per cent. crossing-over with the latter gene. In this author's earlier map (Hutt, I949) its locus was put at I I cross-over units below $S$. However, as Punnett pointed out, there was enough variation in the determinations by different investigators to justify some doubt about the validity of an estimate derived from the pooled data. In one case, although 576 chicks were classified, the number in

TABLE 5

Tests for linkage of $\mathrm{K}$ with $\mathrm{B}$ and $\mathrm{S}$

\begin{tabular}{|c|c|c|c|c|c|c|c|}
\hline Year & Male & $\begin{array}{l}\text { Coupling } \\
\text { or }\end{array}$ & \multicolumn{4}{|c|}{ Chicks } & $\begin{array}{c}\text { Crossing- } \\
\text { over, }\end{array}$ \\
\hline \multicolumn{3}{|c|}{ (I) $B$ and $K$} & $B K$ & $b k$ & $B k$ & $b K$ & \\
\hline I 944 & $M 5^{I}$ & $\mathrm{R}$ & 52 & 66 & 57 & 55 & $5^{\mathrm{I}} \cdot 3$ \\
\hline \multirow{3}{*}{ I 944} & \multirow[t]{3}{*}{$\mathrm{M}_{54}$} & $\mathrm{R}$ & I 18 & II 2 & 99 & 75 & $56 \cdot 9$ \\
\hline & & \multirow[t]{2}{*}{ Totals: } & 170 & 178 & I 56 & 130 & \\
\hline & & & \multicolumn{2}{|c|}{$34^{8}$} & \multicolumn{2}{|c|}{286} & $54 \cdot 9$ \\
\hline \multirow{8}{*}{$\begin{array}{l}\text { I } 942 \\
\text { I } 942 \\
\text { I } 944 \\
\text { I } 944 \\
\text { I } 95 \text { I }\end{array}$} & \multirow{8}{*}{$\begin{array}{c}\text { (2) } S \text { and } \\
\mathrm{H} 33\end{array}$} & & $S K$ & $s k$ & $S k$ & $s K$ & \\
\hline & & C & 47 & 40 & o & 0 & $0 \cdot 0$ \\
\hline & & C & 56 & 43 & 2 & o & $2 \cdot 0$ \\
\hline & & C & I39 & I 36 & 5 & 3 & $2 \cdot 8$ \\
\hline & & $\mathrm{C}$ & 203 & 215 & 6 & 8 & $3 \cdot 2$ \\
\hline & & C & $3^{2}$ & 39 & o & 3 & $4^{\cdot I}$ \\
\hline & & \multirow[t]{2}{*}{ Totals : } & 477 & 473 & 13 & I4 & \\
\hline & & & \multicolumn{2}{|c|}{$95^{\circ}$} & \multicolumn{2}{|c|}{27} & $2 \cdot 8$ \\
\hline
\end{tabular}

one cross-over class was nearly five times that in the other, where approximate equality was expected.

More recently, Jaap ( $195^{6}$ ) found in 1596 chicks that cross-overs between $K$ and $S$ numbered only 20, or I 3 per cent. In the studies here reported, crossing-over between these two genes was $2 \cdot 8$ per cent. in 977 gametes, and the separate determinations for the 5 males were fairly consistent (table 5).

This figure would have been somewhat higher if classification as $K$ or $k$ at Io days only had been accepted as correct. The restriction that cross-overs were accepted as such only when classification at io days agreed with that at hatching, did lower slightly the number of crossovers recorded. On the other hand, putting the locus of $K$ at 2.8 from $S$, as our data have it, does permit an orderly plan (fig. I) based on I I different relationships in that end of the chromosome. The arrangement and distances shown in that plan would not be equally feasible 
if the distance between $S$ and $K$ were 15 units or more, as the earlier determinations had it. As expected, $K$ was found to be quite independent of $B$ (table 5).

Some years ago Dr. E. F. Godfrey, then at the University of Tennessee, tested the relationships of $B, K$, and $S$, and he has kindly provided the following extensive data (not published elsewhere) for inclusion in this report.

\begin{tabular}{cccc} 
Genes & Parental & \multicolumn{2}{c}{ Cross-overs } \\
combinations & Number & Per cent. \\
$B$ and $K$ & 909 & 863 & $48 \cdot 7$ \\
$B$ and $S$ & 564 & 441 & $43 \cdot 9$ \\
$S$ and $K$ & 934 & 73 & $7 \cdot 2$
\end{tabular}

Godfrey's $7 \cdot 2$ per cent. and Jaap's I 3 fit our map better than any of the earlier determinations for $K$ and $S$. It is worth noting also that, whereas the cumulative data for the $B-S$ and $B-K$ linkages, as summarised by Punnett, would put $K$ slightly closer than $S$ to $B$, Godfrey's figures indicate a locus for $K$ a little below $S(4 \cdot 8)$, a position that is in accord with all the relationships shown in fig. $\mathrm{I}$.

\section{THE MAP}

The various relationships determined from the data in tables I to 5 permit construction of the maps shown in fig. $\mathrm{I}$. There are no inconsistencies, and the two minor discrepancies are no greater than could be expected by chance in comparatively limited numbers and with genes very close together. Thus, $S$ and al both showed the same crossing-over with $d w$, but the map separates $S$ and al by only I $\cdot 2$ units. Similarly, $a l$ and $K$ both showed 17.6 per cent. crossing-over with $n$, but that is not surprising as the map has al and $K$ only $I \cdot 6$ units apart.

The highest cross-over percentage observed, 28.9 between $a l$ and $s h$, is not out of line with the total distance between these genes as determined from the sum of its component segments, which is $34^{\circ} 6$. Presumably double crossing-over in that distance would reduce somewhat the number of detectable cross-overs between the two genes at the extreme ends. Similarly, when Mueller's figures are added to the present ones for the $K$-sh linkage, cross-overs in the combined data number 25.6 per cent. The map distance made up from shorter segments is 33 .

In fig. I, the map on the right shows the positions of 13 genes located thus far in the fowl's sex chromosome. The major part, that from ko to $S$, is unchanged from the map of 1949 , except that $S d$ is shown so close to $B$ that the two might be alleles. Unfortunately no studies of $S d$ and its relation to $B$ have been reported since the brief abstract by Munro ( 1946 ). The distance from $S$ to $s h$, as worked out from the studies here reported, covers 35.8 units and thus makes the total map distance known thus far i i $\cdot 8$ units. This is believed to be the longest map to date for any chromosome of a vertebrate animal. 

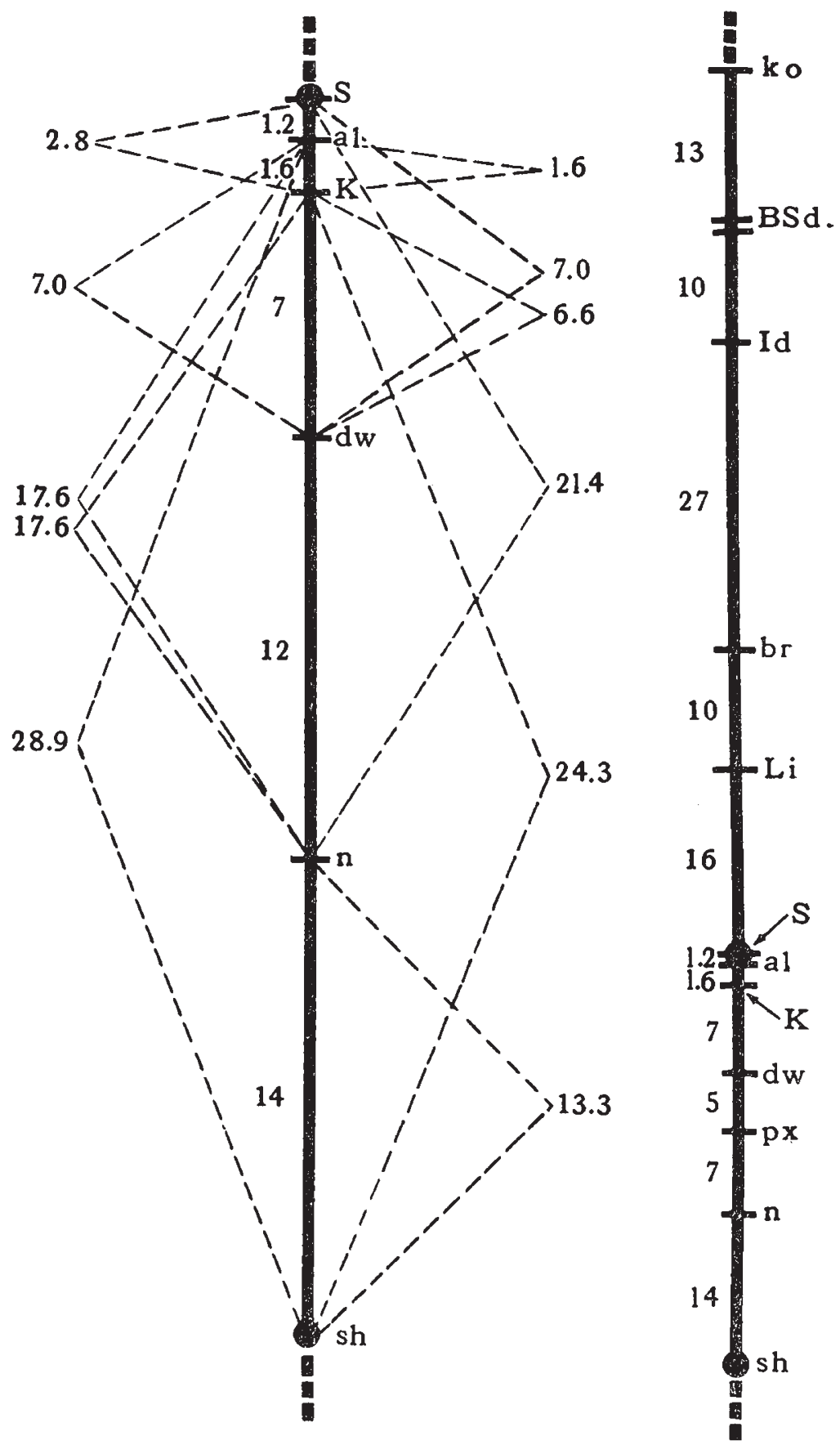

FIG. I.--Diagrams showing (left) linkage relationships and loci of genes considered in this study, and (right) a revised, extended map for the sex chromosome. 
Cole (1958) has reported that the gene $p x$ causing " paroxysm," a syndrome lethal in the first few weeks after hatching, shows 6 per cent. crossing-over with $n$ and 10.5 per cent. with al. With such relations, it fits nicely in the map, as shown, at a point almost equidistant between $d w$ and $n$.

There are two genes known to be sex-linked for which loci are still undetermined. These are the lethals $x l$ (Goodwin et al., I950) and $j$ (jittery). Godfrey et al. (I 953) reported that $j$ is apparently independent of both $B$ and $K$, but there were indications in their data that the order of the genes is most likely $B-K-j$. In two separate tests, one with these three genes in the coupling phase, and the other with males of the genotype $B K j \mid b k \mathcal{F}$, the smallest numbers in the progeny were found in the class that would have been double cross-overs if $K$ were between $B$ and $j$. The map in fig. I, which shows altogether 33 cross-over units below $K$, makes it fairly certain that Godfrey et al. were right in their interpretation, and that $j$ lies far enough below sh to show no significant linkage with $K$ in the 805 gametes that they classified. It seems probable, therefore, that linkage tests with $n$ and sh would be most likely to reveal the locus of $j$, and that the accomplishment would extend the map of the sex chromosome to more than I 40 cross-over units.

In this connection it is worth recalling that the fowl's sex chromosome, which is $\mathrm{V}$-shaped, ranks fifth in length and is less than half as long as the biggest chromosome (Sokolow and Trofimow, r933). In the fowl's four largest autosomes, map distances are likely to be so great that many genes actually within one linkage group could appear to be independent. This helps to explain why so many tests for autosomal linkage have been fruitless (Warren, I949). Only 5 autosomal groups are known, and there is no proof that any two of these do not belong together in some great, long chromosome. If the present maps for the autosomes are to be extended or filled in, it is important that any genes showing the slightest indication of linkage in small numbers of gametes be tested further on a larger scale.

\section{SUMMARY}

Data are given from tests for linkage which were carried out at various times since I 938 with the sex-linked genes for silver $(S)$, albinism $(a l)$, slow feathering $(K)$, dwarf $(d w)$, naked $(n)$ and shaker $(s h)$.

From all the results, together with Mueller's figure for the $K$-sh linkage and Cole's study of paroxysm $(p x)$, the lower end of the sex chromosome was found to carry all these genes, with distances between them as follows: $S_{\text {I }} 2$ al I. $6 K 7 d w 5 p x 7 n$ I 4 sh.

For the whole chromosome, the total distance mapped thus far is I I $\cdot 8$, and the locations of 13 genes in that distance are shown. 


\section{REFERENCES}

COLE, R. K. 1958. Paroxysm-a sex-linked lethal in the fowl. Poultry Sci., 37, I I 94-I I 95 .

GODFREY, E. F., BOHREN, B. B., AND JAAP, R. G. I 953 . "Jittery," a sex-linked nervous disorder in the chick. F. Hered., 44, I08-I I 2.

GOODWIN, K., HUTT, F. B., AND COLE, R. K. I950. A sex-linked lethal gene in the fowl. Science, $112,460-46 \mathrm{I}$.

hUtт, F. в. I936. Genetics of the fowl. VI. A tentative chromosome map. Neue Forsch. in Tierzucht u. Abst. (Duerst Festschrift), I05-I I2. Bern. Verbandsdruckerei.

hUtт, F. B. I 949 . Genetics of the Fowl. New York, London. McGraw-Hill.

hUtт, F. B. I959. Sex-linked dwarfism in the fowl. f. Hered., 50, 209-22 I.

HUTt, F. B., AND STURKIE, P. D. I938. Genetics of the fowl. IX. Naked, a new sex-linked mutation. F. Hered., 29, 370-279.

JAAP, R. G. I956. Late feathering closely linked with Columbian color in chickens. Poultry Sci., 35, 490.

MUELLER, C. D. I952. Linkage relationships of the gene for " shaker" in chickens. Poultry Sci., 31, I 105-I I06.

MUELleR, C. D., AND HUtT, F. B. I94I. Genetics of the fowl. I2. Sex-linked, imperfect albinism. F. Hered., 32, 7I-80.

MUnRo, s. s. 1946. A sex-linked true-breeding blue plumage colour. Poultry Sci., $25,408$.

PUNNETT, R. C. I940. Genetic studies in poultry. X. Linkage data for the sex chromosome. F. Genet., 39, 335-342.

SCOTT, H. M., MORRILl, C. C., ALbERTs, J. O., AND ROBERTS, E. I95O. The "shaker" fowl-a sex-linked semi-lethal nervous disorder. f. Hered., 4I, 254-257.

sokolow, N. N., AND TROFIMOW, I. E. I933. Individualität der Chromosomen und Geschlechtsbestimmung beim Haushuhn (Gallus domesticus). Zeit. ind. Abst.Vererb., 65, 327-352.

WARREN, D. C. I949. Linkage relations of autosomal factors in the fowl. Genetics, $34,333-350$. 